\title{
DRUG PROFILE OF PATIENTS WITH SYSTEMIC LUPUS ERYTHEMATOSUS IN TIMES OF COVID-19 PANDEMIC IN
} \section{AMAZONAS}

Joelma Moreira Belas Torres ${ }^{1, \star}$, Bárbara Letícia Costa Corrêa ${ }^{1}$, Gabriela Alarcón Alcântara ${ }^{1}$, Samuel Elias Basualto Dias ${ }^{1}$, Clara Pinheiro Martins ${ }^{1}$, Andrezza Mendes Franco ${ }^{1}$, Vitória Miki Pang Takatani ${ }^{1}$, Cecília Tizatto Barroso ${ }^{1}$, Gabriella Bacellar Marques ${ }^{1}$, Bruna Borges Santos ${ }^{1}$, Gabriel Antônio de Lima Cerqueira ${ }^{1}$, Bruna Guimarães Dutra ${ }^{1}$, Laura Ribeiro Aref Kzam ${ }^{1}$, Bárbara Seabra Carneiro $^{1}$, Helena Lúcia Alves Pereira ${ }^{1}$, Sandra Lúcia Euzébio Ribeiro ${ }^{1}$

1.Universidade Federal do Amazonas, Manaus (AM), Brazil.

${ }^{*}$ Corresponding author: joelmatorress.jt@gmail.com

\section{BACKGROUND}

Systemic lupus erythematosus (SLE) is a chronic autoimmune and inflammatory disease with multisystemic involvement that requires in addition to drug treatment, general measures of orientation and control of comorbidities. Antimalarials (AM) and glucocorticoids play a crucial role in modulating the immune system and can prevent exacerbation of SLE and induce its control or remission. The presence of a viral or bacterial infection and changes in treatment doses can lead to increased disease activity. The objective of the study is to evaluate the drug profile and the interruption of this treatment during the coronavirus disease 2019 (COVID-19) pandemic in patients with SLE in Manaus, state of Amazonas.

\section{MATERIALS AND METHODS}

A prospective, observational and descriptive study based on data from the Mario Pinotti II Project in the REDCap platform. The study included 313 patients with immune-mediated rheumatic disease (IMRD) in chronic use of AM, between April and September 2020, in Manaus. Information on treatment and adherence to flu symptoms in patients diagnosed with SLE were extracted. The study was approved by the Ethics Committee.

\section{RESULTS}

Of the 313 patients with IMRD, 272 were diagnosed with SLE. Regarding the medication used, 257/272 (94.5\%) used one or more medications in association with AM, while 15 (5.5\%) used isolated AM. The medications most associated with AM were oral corticoid 177 (68.9\%), azathioprine 59 (22.9\%) and mofetil mycophenolate 30 (11.7\%). One hundred and fifty patients with SLE complained of flu symptoms. Concerning the drug regimen: $137 / 150$ (91.3\%) continued with the same medication, and only 13 ( $8.6 \%$ ) reported changes in the medication, most of them in the corticoid dosage.

\section{CONCLUSION}

In this study, we observed that the rate of drug discontinuation in patients was low. This had a positive impact on the control of SLE since most of them did not suffer negative impacts from flu symptoms during the COVID-19 pandemic. 